\title{
Morphofunctional characterization of elderly women according to depressive symptomatology
}

\author{
Sônia Merian Guimaraes', Cristiano Garcia da Silva', Roberta Luksevicius Rica², Adriano Fortes Maia', \\ Angélica Castilho Alonso ${ }^{2}$, Gustavo Alegretti João ${ }^{4}$, Fabio Ceschini ${ }^{4}$, Danilo Sales Bocalini'.
}

\begin{abstract}
Introduction: Aging is an irreversible physiological process that promote changes on biological parameters that culminate in limitations in the execution of daily tasks Objective: Evaluate the morphofunctional parameters of the elderly with and without depressive symptomatology. Methods: A cross-sectional descriptive exploratory study was carried out using the protocol of evaluation of the functional autonomy of the Latin American Development Group for Maturity (GDLAN Protocol), consisting of walking 10 meters $(\mathrm{C} 10 \mathrm{~m})$, rising from the sitting position (LPS), rising from the ventral position (LPDV) and rising from a chair and moving around the house (LCLC). Results: No significant differences $(p>0.05)$ were found between the groups on functional tests and anthropometric parameters, however, statistical differences $(p=0.001)$ were found between the groups in the general GDLAM index. Additionally, a positive correlation $\left(r^{2}: 0.778 ; p<0.01\right)$ was observed between the scores of depressive symptomatology and the general index GDLAM indicating that impairments in functional fitness proportionally higher incidence of depressive symptoms. Conclusion: The results suggest that elderly women with a depressive symptom present lower physical fitness than elderly women without symptoms of depression, and that physical activity is necessary for both samples to contribute to the improvement of daily life activities.

Keywords: Aging; Functional Fitness; Depression; Antropometry.
\end{abstract}

\section{INTRODUCTION}

Aging is an irreversible physiological process that occurs in the body and implies a series of biological situations that culminate in limitations in the execution of daily tasks ${ }^{(1)}$. It is also defined as a natural, individual, socio-vital process throughout the course of life, influenced by lifestyle. The age-old phase in society is closely associated with the expression "to be old", a condition that results from the aging process that every human being inevitably lives or will live within diverse social, political and individual contexts ${ }^{(2,3)}$. United Nations data show that $12.3 \%$ of the world's population is over 60 years of age and expects by 2030 an increase of $16.5 \%$ and by 2050 an increase of $21.5 \%$, representing 2 billion people. These demographic changes will happen more rapidly in developing countries, such as Brazil, which has been showing declines in the birth rate and increase in life expectancy, contributing to the increase in the elderly population. With aging, the elderly, for many reasons, feel excluded and devalued, thus senior citizen social centers become spaces in which the elderly can develop various activities and reverse this situation. The participation of the elderly in cohabitation groups leads to learning, since they share ideas, experiences, socialize, have fun and also reflect on the daily life of this group of people ${ }^{(4,5)}$. In view of the aging process, the social centers gain a significant importance in the life of the elderly, because the elderly socialize, practice intellectual, cultural and leisure activities, and in a way, become active in society.

However, throughout life, an elderly subjects brings the wear and tear of their own body, and consequently the decrease and difficulty in carrying out activities, causing them to become more and more debilitated and have less opportunities and efficiency to carry out day-to-day activities. However, through different activities, the elderly have, for example, the opportunity to balance this scenario through the regular planned practice of exercises, Any physical exercise program for the elderly is necessary to have as in any other program control of physical training variables in order to improve their physical fitness ${ }^{(6)}$. Thus, the objective of this study was to describe the morphofunctional parameters of elderly women with and without indicators of depressive symptoms.

Corresponding Author: Danilo Sales Bocalini. Universidade Federal do Espírito Santo. Centro de Educação Física e Desportos. Av. Fernando Ferrari, 514, Campus Universitário Goiabeiras, Vitória, ES, CEP:29075810. bocaliniht@hotmail.com, Phone: (55)-27-40092620

${ }^{1}$ Experimental Physiology and Biochemistry Laboratory. Physical Education and Sport Center. Universidade Federal do Espirito Santo, Vitoria, ES, Brazil. Full list of author information is available at the end of the article.

Financial support: nothing to declare

Submission date 21 December 2018; Acceptance date 11 February 2019; Publication date 13 March 2019 


\section{MATERIAL AND METHODS}

\section{Sample}

After the approval of the Etical Research Committee (007/2018), elderly women attending the Senior Citizen Cohabitation Center of the Municipality of Vitória voluntarily participated in this study. Excluded were older women that were using antidepressant medications or any skeletal and metabolic muscle complications that would prevent the performance of functional testing procedures as well as cognitive alterations and illiteracy. All subjects were informed about the procedures performed and signed an informed consent form, as well as the sociodemographic. Therefore, the sample consisted of 71 elderly women (> 60 years), enrolled active attendees (minimum three days a week).

\section{Evaluated parameters}

\section{Anthropometric evaluation}

Height was measured to the nearest $0.1 \mathrm{~cm}$ using a Cardiomed stadiometer (WCS model, Cardiomed, Curitiba, Brazil). Body mass was measured to the nearest $0.1 \mathrm{~kg}$ using a Filizola scale (Personal Line 150 model, Filizola, São Paulo, Brazil). BMI $\left(\mathrm{kg} / \mathrm{m}^{2}\right)$ was calculated as follows: $\mathrm{BMI}=$ weight/height ${ }^{2}$. Body composition was determined using anthropometric measures according by our group ${ }^{(7,8)}$.

\section{Depressive symptomatology}

For the evaluation of depressive symptoms, an effective instrument was used to identify symptoms of depression in the elderly, both in clinical context and in research. The Geriatric Depression Scale ${ }^{(9)}$ reduced version of 15 items (GDS-15) and is considered a reference for evaluation of depressive symptoms in the geriatric population and has been used in numerous studies ${ }^{(10-13)}$. The instrument consists of 15 items and consists of dichotomous answers (yes or no). It's score ranges from 0 to 15 points and includes the following cutoff points: less than 5 points meaning normal or no depressive symptoms; greater than or equal to 5 points, an individual with depressive symptoms. In this study, the cut-off point $\geq 5$ was used as indicative of symptoms of depression and $<5$ with no indication of symptoms of depression ${ }^{(12,13)}$.

\section{Functional fitness}

Functional fitness was assessed by the functional autonomy protocol of maturity of the Latin American development group (GDLAM), proposed by Dantas \& Vale(14) and used by other studies $(15,16)$. The protocol consists of performing the following tests: walk $10 \mathrm{~m}(\mathrm{C} 10 \mathrm{~m})$, rise from a sitting position (LPS), rising from the prone position (LPDV) and rising from a chair and moving around the house (LCLC). All tests were performed in the order described above, in a single day, using a 3 minute interval between each to allow good recovery between tests. According to Dantas \& Vale(14), the results the GDLAM General Index (functional index) were evaluated considering the following equation: $I G=[(C 10 m+L P S+L P D V) \times 2]$

\section{Statistical analysis}

Data (means + SEM) were analyzed using the GraphPad Prism software (version 4.0, San Diego, CA, USA). T-student test was used to identify differences between groups. The significance level was set at $p<0.05$.

\section{RESULTS}

After analysis of the Geriatric Depression Scale, 71 elderly women $(p<0.01)$ had depressive symptoms $(7.44 \pm 2.48)$ and 46 had no symptoms $(1.54 \pm 1.92)$. Table 1 shows the socioeconomic parameters.

As shown in Table 2, no statistical differences ( $p>0.05)$ were found between groups in all anthropometric parameters.

No significant differences $(p>0.05)$ were found between the groups on functional tests (Table 3 ). However, statistical

Table 1. Socioeconomic parameters of elderly women according to depressive symptomatology

\begin{tabular}{|c|c|c|c|c|c|}
\hline \multirow{3}{*}{ Parameters } & \multicolumn{4}{|c|}{ Depression } & \multirow{3}{*}{ Significance } \\
\hline & \multicolumn{2}{|c|}{$\begin{array}{c}\text { With } \\
\text { symptoms }\end{array}$} & \multicolumn{2}{|c|}{$\begin{array}{l}\text { Without } \\
\text { symptoms }\end{array}$} & \\
\hline & $n$ & (\%) & $n$ & (\%) & \\
\hline Education & & & & & $p>0.05$ \\
\hline Elementary & 12 & 48 & 17 & 36.95 & \\
\hline High school & 6 & 24 & 23 & 50 & \\
\hline Secondary school & 4 & 16 & 4 & 8.69 & \\
\hline No education & 3 & 12 & 2 & 4.34 & \\
\hline Marital Status & & & & & $p<0.05$ \\
\hline Widow & 5 & 20 & 21 & 45.65 & \\
\hline With companion & 9 & 36 & 14 & 30.43 & \\
\hline Without companion & 11 & 44 & 11 & 23.91 & \\
\hline Monthly alary & & & & & $p>0.05$ \\
\hline $0-1$ min. salaries & 5 & 8 & 11 & 23.91 & \\
\hline 1 - 3 min. salaries & 20 & 80 & 24 & 52.17 & \\
\hline$>3$ min. salaries & 0 & 0 & 11 & 23.91 & \\
\hline Retired & & & & & $p>0.05$ \\
\hline Yes & 21 & 84 & 37 & 80.43 & \\
\hline No & 4 & 16 & 9 & 19.56 & \\
\hline Working & & & & & $p>0.05$ \\
\hline Yes & 1 & 4 & 6 & 13.04 & \\
\hline No & 24 & 96 & 40 & 86.95 & \\
\hline Medications & & & & & $p>0.05$ \\
\hline Yes & 20 & 80 & 34 & 73.91 & \\
\hline No & 5 & 20 & 12 & 26.08 & \\
\hline
\end{tabular}


Table 2. Anthropometric parameters of older women according to depressive symptomatology

\begin{tabular}{lccc}
\hline \multirow{2}{*}{ Parameters } & \multicolumn{2}{c}{ Depression } & \\
\cline { 2 - 3 } & $\begin{array}{c}\text { With } \\
\text { symptoms }\end{array}$ & $\begin{array}{c}\text { Without } \\
\text { symptoms }\end{array}$ & \\
\hline Age (years) & $71.00 \pm 8.36$ & $71.49 \pm 6.65$ & $p=0.878$ \\
Body mass (kg) & $69.26 \pm 13.12$ & $66.68 \pm 11.06$ & $p=0.407$ \\
Height (m) & $1.53 \pm 0.07$ & $1.53 \pm 0.05$ & $p=0.937$ \\
BMI (kg/m ${ }^{2}$ ) & $29.50 \pm 5.24$ & $28.27 \pm 5.03$ & $p=0.181$ \\
AW $(\mathrm{cm})$ & $100.08 \pm 9.82$ & $96.52 \pm 9.91$ & $p=0.414$ \\
\hline
\end{tabular}

Note: Values expressed in mean \pm standard deviation. BMI: body mass index. AW: abdominal waist.

Table 3. Functional parameters of elderly women according to depressive symptomatology

\begin{tabular}{lccc}
\hline & \multicolumn{2}{c}{ Depression } & \\
\cline { 2 - 3 } \multicolumn{1}{c}{ Parameters } & \multicolumn{1}{c}{$\begin{array}{c}\text { With } \\
\text { symptoms }\end{array}$} & $\begin{array}{c}\text { Without } \\
\text { symptoms }\end{array}$ & Significance \\
\cline { 2 - 3 } & $11.67 \pm 2.75$ & $12.06 \pm 10.97$ & $p=0.875$ \\
C10m (seg) & $10.74 \pm 13.42$ & $8.74 \pm 11.70$ & $p=0.522$ \\
LPDV (seg) & $51.04 \pm 15.18$ & $47.78 \pm 14.01$ & $p=0.172$ \\
LCLC(seg) & $15.37 \pm 4.49$ & $14.67 \pm 5.89$ & $p=0.472$ \\
LPS (seg) & $109.01 \pm 42.94$ & $36.23 \pm 28.75$ & $p=0.001$ \\
IG & &
\end{tabular}

Note: Values expressed in mean \pm standard deviation. C10m: andar 10 metros, LPS: levantar-se da posição sentada, levantar-se da posição em decúbito ventral (LPDV) e levante-se da cadeira e locomover pela casa (LCLC). IG: index GDLAM.

differences ( $p=0.001$ ) were found between the groups in the general GDLAM index.

Additionally, as shown in Figure 1, a positive correlation ( $r 2: 0.778 ; p<0.01$ ) was observed between the scores of depressive symptomatology and the general index GDLAM indicating that impairments in functional fitness proportionally higher incidence of depressive symptoms.

\section{DISCUSSION}

Depression is a disease considered to be one of the major public health problems, with high incidence around the word $^{(1,17,18)}$. Although the disease can affect people at any stage of life, some studies indicate that symptoms are highly prevalent later in life. Stress factors such as retirement, death of spouse, lack of future perspective, and loneliness can add to the losses of age and trigger psychic manifestations of depression. Additionally, Stella et al. ${ }^{(19)}$ showed that depression is present in $15 \%$ of elderly people living in the community and $30 \%$ in institutionalized elderly people, which together with dementia make it one of the most common mental disorders found in the elderly. Although in our study there were no differences between the groups with and without depressive symptoms considering socioeconomic factors,

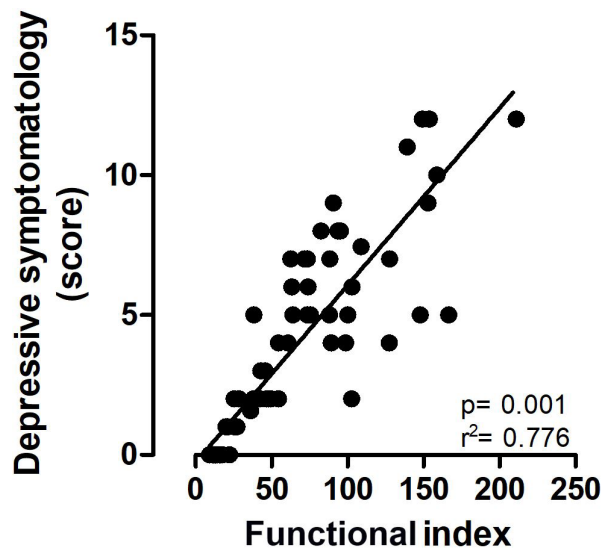

Figure 1. Linear correlation of depressive symptomatology and functional index

it is known that changes in social roles, such as retirement can lead to a decrease in self-esteem, daily activities and of interest in day-to-day life. The loss of close companions, such as spouse, children or friends, also acts as a trigger for depressive symptoms ${ }^{(20)}$. In addition, low schooling and increasing age are considered predictive factors of higher scores of depressive symptoms ${ }^{(21)}$. The influence is also highlighted of monthly low income and average consumption above three daily medications with direct implication in increasing the chance of developing a depressive scenario ${ }^{(12)}$. It is seen that monthly income is considered one of the essential elements for the maintenance of autonomy and preservation or recovery of health. Another important component in this scenario corresponds to job, Amorim et al. ${ }^{(22)}$ consider considered the occupational activity such an important mechanism to protect against depression, disability and mobility, as well as maintaining well-being and independence in daily activities.

Curiously, Blay et al. ${ }^{(23)}$ found that the highest prevalence corresponds to elderly women with weakened health, functional status decline, chronic diseases installed in addition to low social status. In contrast, our study does not showed differences between economic and social conditions; however, the elderly with depressive symptomatology presented worse functional status corroborating with their affirmations. Additionally, Ribeiro et al. ${ }^{(24)}$ showed that the low level of physical activity had been considered such a factor of non-engagement of the elderly women in a health promotion, even when controlled for sociodemographic and demonstrating that not performing physical activity is a factor not participate in activities that promote their health. Nascimento et al. ${ }^{(25)}$ using training of 16 weeks, showed a significantly positive improvement was achieved for the general physical fitness level and also that the aging process seems to reduce these levels in sedentary people. Still, from the point of view of mental health, in the elderly, psychomotor slowness and lack of physical mobility causes low self-esteem, decreased participation in the community and a reduction in 
the circle of social relations. As a consequence, they lead to injuries and finally generate a decrease in physical fitness ${ }^{(26)}$. Incidentally, studies of the Functional Assessment by the Lawton Scale for instrumental activities of daily living (ADL), aimed to measure functional autonomy and analyze the decline of cognition and its impact on functional abilities in institutionalized and non-institutionalized elderly with degree of moderate to moderate depression, which concludes that the institutionalized elderly have a lower cognitive performance that leads to impairment of functional abilities and consequent increase in depression compared to the elderly who socialize and participate in some physical activity ${ }^{(27)}$.

However, it is a consensus that changes in physical fitness parameters directly affect the functional capacity of the elderly: In this context, Maciel ${ }^{(28)}$ concludes that adopting an active lifestyle provides several health benefits, since it is considered an important component for improving the quality of life and functional independence of the elderly. Alves et al. ${ }^{(29)}$ observed a significant improvement in all physical fitness tests applied after training with water gymnastics classes. This seems to prove the importance of practicing physical exercise in the case of hydrogymnastics in the maintenance and improvement of physical fitness of elderly women who lead a life without regular physical exercise. The results of this study are consistent with other studies ${ }^{(17,30)}$, which investigated the effects of physical activity practice with the aim of improving physical and functional fitness as an alternative treatment of symptoms of depression among the elderly. Gool et al. ${ }^{(30)}$ in a prospective, longitudinal study (6 years) with $n=1280$, shows that the incidence and remission of depression are directly related to the reduction and increase of physical activity practice. Strawbridge et al. ${ }^{(17)}$ found a significant difference in the symptoms of depression between the active and non-active groups, where the group that practiced fewer exercises had a higher prevalence and incidence of depression.

\section{CONCLUSION}

Although there were no differences between the anthropometric parameters and in the isolated tests of functional fitness, elderly women with depressive symptoms showed losses in the general functional capacity indicator, and this proportion was proportionally worsened as the symptom score increased.

\section{AUTHOR'S CONTRIBUTION}

SMG, CGS and DSB elaborated the study design; SMG and CGS performed the data collection; RLR and AFM performed the statistical analysis; ACA, GAJ, FC and performed the critical intellectual revision of the manuscript. All authors read and approved the final manuscript.

\section{COMPETING INTERESTS}

The author(s) declare that they have no competing interests.

\section{AUTHORS DETAILS}

${ }^{2}$ Department of Physical Education. Universidade Estacio de Sá, Vitoria, ES, Brazil. ${ }^{3}$ Department of Post-Graduation in Aging Science. Universidade São
Judas Tadeu, São Paulo, SP, Brazil. “Department of Physical Education. Centro Universitário FMU, São Paulo, SP, Brazil.

\section{REFERENCES}

1. Rica RL, Miranda MLJ, Evangelista AL, Polito LFT, Serra AJ, Figueira Junior A, Gama EF, Alonso AC, Bocalini DS. Contribuições da atividade física no tratamento de idosos com transtorno depressivo: uma breve revisão. Revista Corpoconsciência. 2014; 19(2): 21-33.

2. Lehtinem V, Joukamaa M. Epidemiology of depression: prevalence, risk factors and treatment situation. Acta Psychiatrica Scandinavica. 1993; 89.7-10, S377.

3. Neri $A L$, Jorge MD. Atitudes e conhecimentos em relação à velhice em estudantes de graduação em educação e em saúde: subsídios ao planejamento curricular. Estudos de Psicologia. 2006; 23(2): 127-137.

4. Ramos LR. Fatores determinantes do envelhecimento saudável em idosos residentes em centro urbano: Projeto Epidoso, São Paulo. Caderno de Saúde Pública. 2003; 19(3): 793-8.

5. Rizzolli D, Surd A. Percepção dos idosos sobre grupos de terceira idade. Revista Brasileira de Geriatria e Gerontologia. 2010. 13, 2, 225-233.

6. Civinski C, Montibeller A, Oliveira A. A importância do exercício físico no envelhecimento. Revista da UNIFEBE. 2011. 1, 09.

7. Bocalini DS, Lima LS, de Andrade S, Madureira A, Rica RL, Dos Santos RN, Serra AJ, Silva JA Jr, Rodriguez D, Figueira A Jr, Pontes FL Jr. Effects of circuit-based exercise programs on the body composition of elderly obese women. Clinical interventions in aging. 2012, 7: 551-556.

8. Rica RL, Carneiro RMM, Serra AJ, Rodriguez D, Pontes Junior FL, Bocalini DS. Effects of water-based exercise in obese older women: Impact of short-term follow-up study on anthropometric, functional fitness and quality of life parameters. Geriatrics \& Gerontology International. 2013, 13 (1): 209-214.

9. Yesavage JA, Brink TL. Development and Validity of a geriatric depression screening scale: a preliminary report. J Psychiatr Res. 1983, 17: 37-49.

10. Boström G, Conradsson M, Rosendahl E, Nordström P, Gustafson Y, Littbrand $\mathrm{H}$. Functional capacity and dependency in transfer and dressing are associated with depressive symptoms in older people. Clinical interventions in aging. 2014, 9: 249-256.

11. Oliveira S, Santos A, Pavarini S. Relação entre sintomas depressivos e a funcionalidade familiar de idosos institucionalizados. Revista da Escola de Enfermagem da USP. 2014, 48: 66-72.

12. Hoffmann EJ, Ribeiro F, Farnese JM, Lima EWB. Sintomas depressivos e fatores associados entre idosos residentes em uma comunidade no Norte de Minas Gerais, Brasil. J Bras Psiquiatr. 2010, 59(3): 190-97.

13. Pontes M. Qualidade de vida e fragilidade em idosos que residem em comunidades. 2013. Tese de Doutorado. Universidade de São Paulo.

14. Dantas E, Vale R. Protocolo GDLAN de avaliação da autonomia funcional. Fitness \& Performance Journal. 2004, 3(3): 176-182.

15. Meneses Y, Cabral PU, Abreu FM, Vale RG, Rocha FC, de Andrade AD. Correlation between the carotid resistance and functional autonomy of old women. Revista Brasileira de Enfermagem. 2007, 60(4): 382-386.

16. Suzuki FS, Evangelista AL, Teixeira CVLA, Paunksnis MRR, Evangeista RAGT, João GA, Doro MR, Sita DM, Serra AJ, Figueira Junior AJ, Alonos AC, Peterson M, Bocalini DS. Effects of a multicomponent exercise program on the functional fitness in elderly women. Revista Brasileira de Medicina do Esporte. 2018, 24(1): 36-39.

17. Strawbridge W, Deleger S, Roberts RE, Kaplan GA. Physical activity reduces the risk of subsequent depression for older adults. American journal of epidemiology. 2002, 156(4): 328-334.

18. Irigaray $\mathrm{TQ}$, Schneider RH. Prevalência de depressão em idosas participantes da Universidade para a Terceira Idade. Revista de Psiquiatria. 2007. 19-27.

19. Stella F, Gobbi S, Corazza DI, Costa JLR. Depressão no idoso: diagnóstico, tratamento e benefícios da atividade física. Motriz. 2002, 8(3): 90-98. 
20. Irigaray T, Schneider R. Prevalência de depressão em idosas participantes da Universidade para a Terceira Idade. Rev. Psiquiatria. 2007, 29(1): 19-27.

21. Maciel A, Guerra R. Prevalência e fatores associados à sintomatologia depressiva em idosos residentes no Nordeste do Brasil. Jornal Brasileiro de Psiquiatria. 2006, 55(1): 26-33.

22. Amorim J, Salla S, Trelha S. Fatores associados à capacidade para o trabalho em idosos: revisão sistemática. Rev Bras Epidemiol. 2014, 17(4): 830-841.

23. Blay S, Bickel H, Cooper B. Mental illness in a cross-national perspective. Social psychiatry and psychiatric epidemiology. 1991, 26(6): 245-251.

24. Ribeiro RM, Tribess S, Santos AS, Pinto LLT, Ribeiro MCL, Roza LB, Junior JSV. Barreiras no engajamento de idosos em serviços públicos de promoção de atividade física. Ciência \& Saúde Coletiva. 2015, 20(3): 739-749.

25. Nascimento DCD, Brito MACD, Santos AD. Depressão em idosos residentes em uma instituição asilar da cidade de Juazeiro do Norte, Ceará, Brasil. Journal of Management and Primary Health Care. 2014, 4(3): 146-150.
26. Antes D, Rossato LC, Souza AG, Benedetti TRB, Borges GF, Mazo GZ. Índice de aptidão funcional geral e sintomas depressivos em idosos. Rev. Bras. Cineantropom. Desempenho Hum. 2012, 14(2): 125-133.

27. Trindade A, Barboza MA, Oliveira FB, Borges APO. Repercussão do declínio cognitivo na capacidade funcional em idosos institucionalizados e não institucionalizados. Fisioterapia em Movimento. 2017, 26(2): 281-289.

28. Maciel M. Atividade física e funcionalidade do idoso. Motriz. 2017, 16(4): 1024-1032.

29. Alves R, Soares HLR, Teixeira JAC. Benefícios da atividade física e do exercício físico na depressão. Revista do Departamento de Psicologia, Niterói. 2007, 19(1): 269-276.

30. Van Gool C, Kempen GI, Penninx BW, Deeg DJ, Beekman AT, Van Eijk JT. Relationship between changes in depressive symptoms and unhealthy lifestyles in late middle aged and older persons: results from the Longitudinal Aging Study Amsterdam. Age and ageing. 2003, 32(1): 81-87. 